\title{
Inhibition of Specificity Protein 1 Is Involved in Phloretin- Induced Suppression of Prostate Cancer
}

\author{
Dan Kang, ${ }^{1}$ Wenren Zuo, ${ }^{2}$ Qingxin Wu, ${ }^{1}$ Qingyi Zhu, ${ }^{2}$ and Ping Liu ${ }^{1}{ }^{1}$ \\ ${ }^{1}$ College of Life Sciences, Nanjing Normal University, Nanjing, Jiangsu 210023, China \\ ${ }^{2}$ Central Laboratory, Jiangsu Province Hospital of Chinese Medicine, Affiliated Hospital of Nanjing University of Chinese Medicine, \\ Nanjing, Jiangsu 210029, China
}

Correspondence should be addressed to Ping Liu; liuping0805@njnu.edu.cn

Received 11 May 2020; Revised 5 July 2020; Accepted 7 July 2020; Published 11 August 2020

Academic Editor: Giandomenico Roviello

Copyright (C) 2020 Dan Kang et al. This is an open access article distributed under the Creative Commons Attribution License, which permits unrestricted use, distribution, and reproduction in any medium, provided the original work is properly cited.

Phloretin is a flavonoid existed in various plants and has been reported to possess anticarcinogenic activity. However, the anticancer mechanism of phloretin in prostate cancer (PCa) remains unclear. Here, our in vitro and in vivo experimental data demonstrate that phloretin inhibits the phosphorylation and the activation of EGFR and then inhibits its downstream PI3K/AKT and MEK/ERK1/2 pathways in PCa cells. Inhibition of these two pathways further decreases expression of Sp1 by inhibiting Sp1 gene transcription, induces degradation of Sp1 protein by inhibiting GSK3 $\beta$ phosphorylation, suppresses nucleolin-enhanced translation of Sp1 mRNA by inhibiting nucleolin phosphorylation, and directly inactivates transcription activity of Sp1. Inhibition of Sp1 subsequently decreases the expression of Sp3/4, VEGF, and Survivin and then upregulates apoptosis-related proteins and downregulates cell cycle-related proteins in PCa cells. Finally, phloretin treatment in PCa cells induces cell growth inhibition and apoptosis, suggesting that phloretin may be an effective therapy compound in the treatment of prostate cancer.

\section{Introduction}

Prostate cancer is a commonly diagnosed cancer and the fifth leading cause of cancer deaths in men in the world [1]. Chemoprevention is a promising approach in prostate cancer research, in which natural or synthetic compounds are often used to prevent this malignant disease [2]. Phloretin, a natural flavonoid found mostly in plants $[3,4]$, has been reported to possess anticancer activity by inducing apoptosis in human glioblastoma cells, Hep G2 cells, and lung carcinoma cells [5-7], while its anticancer molecular mechanism on prostate cancer is still not well known.

Specificity protein (Sp) transcription factors (Sp1/Sp3/Sp4) are often overexpressed in colon cancer, pancreatic cancer, bladder cancer, breast cancer, prostate cancer, and many other cancers [8-12]. The importance of Sp transcription factors (Sps) as drug targets is due to not only their overexpression in multiple cancers but also their relatively low expression in noncancer human tissues [13-15]. Sp-targeted genes are all important in many cellular physiological processes including cell proliferation (such as Sps, AR, and Cyclin D1), cell survival (such as XIAP and Survivin), and angiogenesis (such as VEGF) [16-19].

The PI3K/AKT and MEK/ERK1/2 signal pathways play the crucial roles in cancer cell survival, growth, migration, and invasion $[20,21]$. Activation of the PI3K/AKT pathway upregulates the levels of AKT-mediated Sp1 phosphorylation and the activity of Sp1 [22, 23]. Also, activation of AKT inhibits GSK3 $\beta$ by increasing the levels of AKT-mediated GSK3 $\beta$ phosphorylation. GSK3 $\beta$-mediated Sp1 phosphorylation at Ser728/Ser732 is critical in promoting Sp1 protein ubiquitination and degradation [24]. In addition, ERKphosphorylated Sp1 at T739/T453 enhances Sp1 binding to DNA and then increases Sp1 transcriptional activity [25-27].

Nucleolin, a multifunctional protein localized not only in the nucleus but also in the cytoplasm and cell membrane, plays an important role in many cellular processes, such as chromatin remodeling, translation of mRNA, transcription of ribosomal RNA (rRNA), rRNA maturation, and ribosome assembly [28]. Usually, nucleolin binds to the G-rich sequence 
in $3^{\prime}$ - or $5^{\prime}$-UTR of target mRNAs and then enhances the translation of target mRNAs [29]. Phosphorylation of nucleolin mediated by VEGF (at Thr76 and Thr84) and EGFR (at Thr641/Thr707) plays a crucial role in binding to and enhancing the translation of target mRNAs [30, 31].

In this study, phloretin treatment in PCa cells decreases the autophosphorylation level of EGFR and its activity and then inhibits its downstream PI3K/AKT and MEK/ERK1/2 pathways. Inhibition of these two pathways subsequently suppresses Sp1 activity by decreasing the expression of Sp1 gene, enhancing the degradation of $\mathrm{Sp} 1$ protein, decreasing the translation of $\mathrm{Sp} 1 \mathrm{mRNA}$, and reducing the DNAbinding of Sp1, and then results in the downexpression of Sp1-targed Sp3/4, VEGF, and Survivin genes. Finally, the levels of Bax, cleaved Caspase-3/-8/-9, and cleaved PARP-1 are upregulated, while the levels of XIAP, Cyclin B1, and $\mathrm{Bcl}-2$ are downregulated, and cell growth inhibition and apoptosis are induced by the treatment of phloretin in PCa cells in vitro and in vivo.

\section{Materials and Methods}

2.1. Cell Lines, Chemicals, Antibody, and Plasmids. Human prostate cancer cell lines (LNCaP, CWR22Rv1, PC-3, and DU145) and normal prostate epithelial cell line (WPMY-1) were purchased from American Type Culture Collection (ATCC) (Manassas, VA, USA). Cell lines were cultured in RPMI 1640 (Wisent, Nanjing, China) containing 10\% FBS (BRL-GIBCO Co. Ltd., CA, USA), penicillin $(100 \mathrm{U} / \mathrm{ml})$, and streptomycin $(100 \mathrm{mg} / \mathrm{ml})$ (Sigma-Aldrich, St. Louis, MO, USA). Cells were maintained at $37^{\circ} \mathrm{C}$ in the presence of $5 \% \mathrm{CO}_{2}$.

Phloretin (>98\%), 5-fluorouracil (5-FU), and CHX (cycloheximide) were purchased from Sigma-Aldrich (St. Louis, MO, USA). CCK-8, MTT (3-(4,5-dimethylthiazol-2-yl)-2,5-diphenyltetrazolium bromide), and MG132 (proteasome inhibitor) were purchased from Beyotime Biotechnology (Shanghai, China). Phloretin and 5-FU were dissolved in DMSO and stocked at $-80^{\circ} \mathrm{C}$, and the stock solutions were diluted in $1 \times$ PBS for in vivo experiments. TRIzol was purchased from Invitrogen (Carlsbad, CA, USA) and the $5 \times$ PrimeScript TM RTPCR system was from Vazyme Biotech (Beijing, China).

Antibodies of Sp1, VEGF, Survivin, androgen receptor (AR), XIAP, PARP-1, Caspase 3, Cyclin D1, Cyclin B1, AKT1/2/3, EGFR, p-EGFR(Tyr1173), and $\beta$-actin were purchased from Santa Cruz Biotechnology (Santa Cruz, CA, USA). Antibodies of Sp3/4, tubulin, H3, p-Sp1(Thr453), p-AKT(Ser473), pERK1/2(T202/Y204), ERK1/2, and p-AKT(Ser308) werepurchased from Bioworld Technology Inc. (Minneapolis, MN, USA). Antibody of p-PI3K was purchased from Cell Signaling Technology (Boston, MA, USA). Antibodies of Caspase8/p18, Caspase9/p35/p10, Bcl-2, BAX, RAF1, GSK3 $\beta$, PI3K p85(alpha), nucleolin, p-Sp1(Thr739), and Ki-67 were purchased from Proteintech Group Inc. (Wuhan, China). Antibodies of $\mathrm{p}$ GSK3(Ser9), p-C-RAF(Ser338), p-MEK1/2(Ser217/Ser221), and MEK1/2 were purchased from Affinity Biosciences Inc. (Cambridge, UK). Antibodies of p-Nucleolin(Thr76) and pNucleolin(Thr84) were purchased from Abcam Company (Cambridge, UK). Goat anti-rabbit IgG-horseradish peroxidase (HRP) and goat anti-mouse IgG-horseradish peroxidase were purchased from Santa Cruz Biotechnology (Santa Cruz, CA, USA).

Nucleolin expression plasmid (pcDNA3.1(+)-nucleolin) and all luciferase reporter plasmids of Sp1-targeted genes, including pSp1(-751/-20)-luc with Sp1 promoter inserts (-751 bp to $-20 \mathrm{bp}$, including four Sp1-binding sites, detailed in [32]), pSp3(-417/-38)-luc with Sp3 promoter inserts ( $-417 \mathrm{bp}$ to $-38 \mathrm{bp}$, including two binding sites in $-185 \mathrm{bp} /-$ $165 \mathrm{bp}$, detailed in [33]), pVEGF(-2018/+50)-luc with VEGF promoter inserts $(-2018 \mathrm{bp}$ to $+50 \mathrm{bp}$, including two binding sites in $-89 \mathrm{bp} /+50 \mathrm{bp}$, detailed in $[22,23,27])$, and pSurvivin(-269/-39)-luc with Survivin promoter inserts (-269 bp to $-39 \mathrm{bp}$, including two binding sites in $-153 \mathrm{bp} /-148 \mathrm{bp}$ and $-140 \mathrm{bp} /-127 \mathrm{bp}$, respectively, detailed in [34]) were constructed by our lab.

2.2. MTT Assay and CCK-8 Assay for Cell Viability and Proliferation. It mainly referred our previous report [35]. In detail, cells were seeded in a 96-well plate at a density of 1 $\times 10^{4}$ cells/well overnight and treated with different concentrations of phloretin $(0,20,50$, and $100 \mu \mathrm{M})$ for $24 \mathrm{~h}$, and then culture medium was removed and fresh medium $(100 \mu \mathrm{l})$ was added with $10 \mu \mathrm{l}$ of MTT $(5 \mathrm{mg} / \mathrm{ml})$ or $5 \mu \mathrm{l}$ of CCK-8 solution. The plate was incubated at $37^{\circ} \mathrm{C}$ for $4 \mathrm{~h}$ in the dark. For CCK- 8 assay, the absorbance of the incubations was measured using a microplate reader (Thermo Scientific, Fremont, CA, USA) at $450 \mathrm{~nm}$. For MTT assay, the medium was removed again, and $100 \mu \mathrm{l}$ of DMSO was added to each well and the absorbance at $570 \mathrm{~nm}$ was measured by a microplate reader (Thermo Scientific, Fremont, CA, USA).

All the measured OD values were converted into cell viability and compared with the value of the control well.

2.3. Cell Apoptosis Analysis by Flow Cytometry and DAPI Staining Assay. Cells cultured in 6-well plates were treated with phloretin $(0,20,50$, and $100 \mu \mathrm{M})$ for $24 \mathrm{~h}$ and then harvested for flow cytometry analysis (cell apoptosis assay) by using an Annexin V-FITC Apoptosis Detection Kit (Keygentec, Nanjing, China) according to the instruction of manufacturer. Flow cytometry analysis for cell apoptosis was performed using the EPICS Elite ESP high-performance cell sorter (Coulter Electronics, Ltd., England, UK) and analyzed by ModFit LT (version 2.0; Verity Software), and a minimum of 30,000 events were collected for each sample.

For DAPI staining assay, cells cultured in 12-well plates were incubated with phloretin $(0,20,50$, and $100 \mu \mathrm{M})$ for $24 \mathrm{~h}$. Cells were briefly washed with $1 \times$ PBS and fixed in $4 \%$ formaldehyde for $15 \mathrm{~min}$, and then washed three times with $1 \times$ PBS and permeabilized in $0.2 \%$ Triton X-100 for $15 \mathrm{~min}$. Finally, cells were stained with DAPI $(1 \mu \mathrm{g} / \mathrm{ml})$ at $37^{\circ} \mathrm{C}$ for $30 \mathrm{~min}$ in the dark and then observed and photographed by fluorescence microscopy (Nikon, IX-71, Japan).

2.4. Cell Cycle Analysis by Flow Cytometry. Cells seeded in 6well plates were treated with phloretin $(0,20,50$, and $100 \mu \mathrm{M})$ for $24 \mathrm{~h}$. Cells were harvested for flow cytometry analysis (cell cycle assay) by using a Cell Cycle Detection Kit (Keygentec, Nanjing, China) according to the instruction of the manufacturer. Flow cytometry analysis for cell cycle 
TABLE 1: The primers used for PCR.

\begin{tabular}{|c|c|c|}
\hline Primers & Sequences $\left(5^{\prime}-3^{\prime}\right)$ & Fragment size (bp) \\
\hline$\beta$-Actin/forward & GAG CTA CGA GCT GCC TGA CG & \multirow{2}{*}{416} \\
\hline$\beta$-Actin/reverse & CCT AGA AGC ATT TGC GGT GG & \\
\hline Sp1/forward & CTG CTA TGC CAA ACC TAC TCC & \multirow{2}{*}{415} \\
\hline Sp1/reverse & CCC TGT AGC CCA CTG ACC CT & \\
\hline SP3/forward & CAA ACC TTA CTT GCC TCT GGA ACA C & \multirow{2}{*}{329} \\
\hline SP3/reverse & TTA ATA TCA GGA GAA ACC CGC TCA C & \\
\hline SP4/forward & AGA AGG AAG AGG CAG TAA TGA ACC A & \multirow{2}{*}{108} \\
\hline SP4/reverse & CGA AGA TGT GCT CGT AAA TGA GAT G & \\
\hline VEGF/forward & GAG GGC AGA ATC ATC ACG AA & \multirow{2}{*}{436} \\
\hline VEGF/reverse & AGG CTC CAG GGC ATT AGA CA & \\
\hline Survivin/forward & CAG ACT TGG CCC AGT GTT TCT & \multirow{2}{*}{235} \\
\hline Survivin/reverse & TTC TCC GCA GTT TCC TCA A & \\
\hline XIAP/forward & CCT TGT GAT CGT GCC TGG TC & \multirow{2}{*}{315} \\
\hline XIAP/reverse & AGG GTC TTC ACT GGG CTT CC & \\
\hline AR/forward & CGG ACG AGG ATG ACT CAG & \multirow{2}{*}{457} \\
\hline AR/reverse & TCT TCA GTG CTC TTG CCT GC & \\
\hline Cyclin D1/forward & CTG CGA AGT GGA AAC CAT CC & \multirow{2}{*}{360} \\
\hline Cyclin D1/reverse & TAG ATG CAC AGC TTC TCG GC & \\
\hline
\end{tabular}

was performed using the EPICS Elite ESP high-performance cell sorter (Coulter Electronics Ltd., England, UK), and a minimum of 20,000 events were collected for each sample. The raw collected data were analyzed by ModFit LT (version 2.0; Verity Software) to determine cell cycle distribution.

\subsection{Immunofluorescent Chemistry and Confocal Microscopy} Assays. Cells cultured in 12-well plates with coverslips were treated with phloretin $(0,20,50$, and $100 \mu \mathrm{M})$. After $24 \mathrm{~h}$, cells grown on coverslips were washed by $1 \times$ PBS and fixed with $2 \%$ paraformaldehyde for $15 \mathrm{~min}$ at room temperature, and then permeabilized by incubating with $0.2 \%$ Triton $\mathrm{X}$ 100 for $15 \mathrm{~min}$. Next, cells were washed three times in $1 \times$ PBS and incubated in blocking buffer (3\% bovine serum albumin in $1 \times$ PBS) for $1 \mathrm{~h}$ at room temperature. After blocking, cells were incubated with $\mathrm{Sp} 1$ and Sp3/4 antibody overnight at $4^{\circ} \mathrm{C}$. Cells were washed with $1 \times$ PBS for three times ( 5 min each) and then incubated with anti-rabbit IgG-FITC secondary antibody (Santa Cruz, CA) in the dark at room temperature for $1 \mathrm{~h}$. Finally, coverslips were washed with $1 \times$ PBS and stained with DAPI in the dark for $8 \mathrm{~min}$. Fluorescent images were captured using a confocal microscope (Nikon, Sendai, Japan).

2.6. Plasmid Transfection and Dual-Luciferase Reporter Assay. Cells were plated in 12-well plates overnight, and the plasmids were transfected by using Lipofectamine 3000 (Invitrogen, Carlsbad, CA, USA). The nucleolin expression plasmid and luciferase reporter plasmids of Sp1-targeted genes were normalized to $1 \mu \mathrm{g}$ per well. At $4 \mathrm{~h}$ after transfection, the transfection mix of each well was replaced with complete media containing different concentrations of phloretin $(0,20,50$, and $100 \mu \mathrm{M})$ for $24 \mathrm{~h}$. Cells were then harvested and lysed for dual-luciferase assay according to the kit instruction
(Beyotime Biotechnology). Relative luciferase units and fold inductions (compared with relative luciferase of control) were calculated by using the measured luciferase values.

2.7. Reverse Transcription-Polymerase Chain Reaction (RT$P C R)$. Cells were cultured and treated with different concentrations of phloretin $(0,20,50$, and $100 \mu \mathrm{M})$. After $24 \mathrm{~h}$, cells were harvested for the extraction of total RNA and RT-PCR ( $\beta$-actin as an internal control) according to the manufacturer's instructions. The primers used for PCR are listed in Table 1.

2.8. Experiments of Cytosolic and Nuclear Extracts. Cells cultured in $60 \mathrm{~mm}$ plates were treated with phloretin as indicated in Figure 1(a). After $24 \mathrm{~h}$, cells were washed with $1 \times$ PBS and harvested for extractions of cytosolic and nuclear proteins by using a Nuclear and Cytoplasmic Protein Extraction Kit (Beyotime Biotechnology). The cytosolic and nuclear extracts were then analyzed by western blot.

2.9. RNA Immunoprecipitation Assay (RIP Assay) and Western Blotting Analysis. Cells were treated with phloretin as indicated in Figure 1(c) and then harvested and lysed with lysis buffer (10 mM HEPES, pH 8.0, $40 \mathrm{mM} \mathrm{KCl,} 3 \mathrm{mM}$ $\mathrm{MgCl}_{2}, 5 \%$ glycerol, $0.5 \% \mathrm{NP}-40$, and $1 \mathrm{U} / \mu \mathrm{l}$ RNaseOUT) for $30 \mathrm{~min}$ on ice. The cell lysates were divided into two parts: one part was for extracting the total RNA and then doing RTPCR for Sp1 $5^{\prime}$-UTR ( $5^{\prime}$-UTR of Sp1 mRNA, as input) and $\beta$-actin (as internal control); another part was for RNA immunoprecipitation (RIP) by incubating with IgG (Beyotime Biotechnology) and anti-nucleolin antibody, and then protein A/G agarose beads (Santa Cruz Biotechnology) at $4^{\circ} \mathrm{C}$ overnight. Immunoprecipitated complexes were washed with lysis buffer and RNA was extracted for RT-PCR of Sp1 


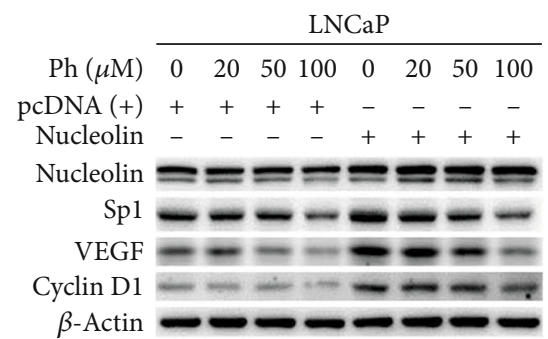

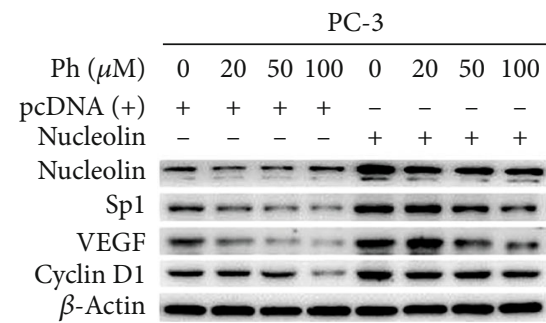

(a)

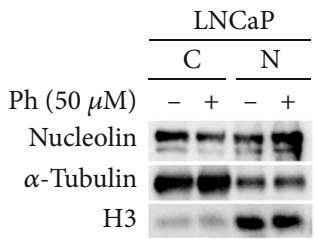

(b)

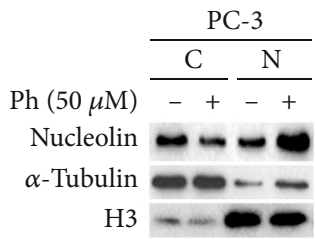

b)

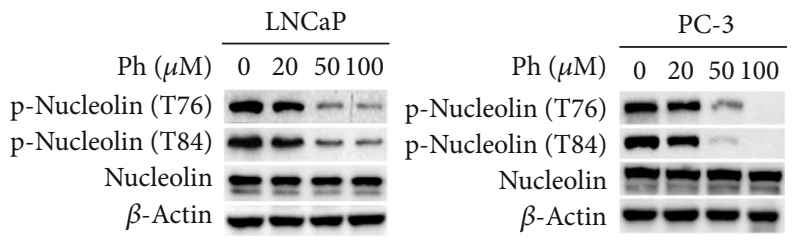

(c)
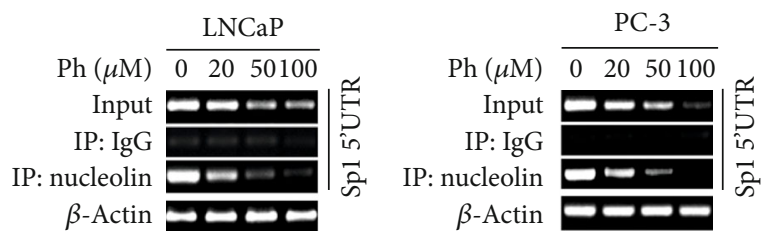

(d)

FIGURE 1: Phloretin decreased Sp1 level by inhibiting nucleolin binding to $5^{\prime}$-UTR of Sp1 mRNA via decreasing the levels of p-Nucleolin(T76 and T84) and regulating the nuclear and cytoplasmic distribution of nucleolin. (a) Cells were treated with different concentrations of phloretin and/or cotransfected with nucleolin expression plasmid, and then cells were harvested for western blotting assay to detect the levels of nucleolin, Sp1, VEGF, and Cyclin D1. (b) LNCaP and PC-3 cells were treated with/without phloretin $(50 \mu \mathrm{M})$ for $24 \mathrm{~h}$ and then harvested for nucleus and cytoplasm separation experiment and western blot assays to check the distribution of nucleolin in the cytoplasm (C) and the nucleus (N). (c) LNCaP and PC-3 cells were treated with phloretin $(0,20,50$, and $100 \mu \mathrm{M})$ for $24 \mathrm{~h}$ and then harvested for western blot assay to check the levels of nucleolin, p-Nucleolin(T76), p-Nucleolin(T84), and $\beta$-actin (loading control). (d) LNCaP and PC3 cells were treated with phloretin $(0,20,50$, and $100 \mu \mathrm{M})$ for $24 \mathrm{~h}$ and then collected for RT-PCR ( $\beta$-actin as internal control and Sp1 $5^{\prime}$ -UTR as input) and RNA-IP with IgG and anti-nucleolin antibody to check the binding levels of nucleolin to $5^{\prime}$-UTR of Sp1 mRNA. The RT-PCR products of mRNAs (including internal control $\beta$-actin mRNA, input Sp1 mRNA, and nucleolin-bound Sp1 mRNAs in the products of RNA-IP with IgG and anti-nucleolin antibody) were assayed by agarose gel electrophoresis.

$5^{\prime}$-UTR. The RT-PCR products were detected with agarose gel electrophoresis. PCR primers specific for Sp1 $5^{\prime}$-UTR were forward, $5^{\prime}$-ACT AGT AGC GAG TCT TGC CAT TGG -3'; reverse, $5^{\prime}$-GG CGC CGG TGG CAG CTG AGG GAC A-3'.

For western blotting analysis, cells were harvested and lysed in radio immunoprecipitation assay (RIPA) buffer (Beyotime Biotechnology) by adding Roche complete protease inhibitor cocktail. After centrifugation and protein quantification, the supernatants (containing total protein 15-30 $\mu$ g) were submitted to western blotting assay with related primary antibodies.

2.10. Antitumor Assay of Phloretin In Vivo. PC-3 cells were calculated by using trypan blue, and finally $2 \times 10^{6}$ cells in $100 \mu \mathrm{l} 1 \times$ PBS were subcutaneously injected into male nude mice (4-5 weeks, supplied by the animal center in the College of Medicine, Nanjing University, Nanjing, China). After tumors grew to $24-30 \mathrm{~mm}^{3}$, mice were randomly divided into four groups ( 5 mice in each group) and treated every two days by intragastrical administration with $1 \times$ PBS (NC group), 5-FU (PC group, $20 \mathrm{mg} / \mathrm{kg}$ ), and phloretin (including the LD group, low dose of $10 \mathrm{mg} / \mathrm{kg}$; the HD group, highdose of $50 \mathrm{mg} / \mathrm{kg}$ ) for six weeks. After 42 days, mice were sacrificed and the subcutaneous tumors were isolated and weighted, and then the tumors were equally dissected into two parts. One part of the tumor tissues was stored at $-80^{\circ} \mathrm{C}$ for western blot assay and another part was formalin fixed and paraffin embedded for immunohistochemistry.

2.11. Immunohistochemistry Analysis. The formalin-fixed tissues were sectioned in 4-5 $\mu \mathrm{m}$ thick. Each tissue section was deparaffinized and rehydrated with upgraded ethanol, and then tissue sections were boiled in EDTA for $15 \mathrm{~min}$, quenched with $0.3 \%$ hydrogen peroxide solution for $10 \mathrm{~min}$ at room temperature, and blocked with BSA in PBS for $30 \mathrm{~min}$. The sections were subsequently incubated with special primary antibodies as indicated in figures overnight at $4^{\circ} \mathrm{C}$ and then counterstained with hematoxylin. Antibody binding was detected with an Envision Detection Kit, 
Peroxidase/DAB, Rabbit/Mouse (Gene Tech, Shanghai, China). The expression levels of specific proteins were observed and photographed under a microscope at a magnification of 400x (CTR 6000; Leica, Wetzlar, Germany).

2.12. Statistical Analysis. All data were expressed as the means \pm SD and analyzed using Student's $t$-test. Comparison between groups was made by the Dunnett test of SPSS in figures. A $P$ value of $<0.05$ was statistically significant. All experiments were replicated three times.

\section{Results}

3.1. Phloretin Induced Morphological Changes and Inhibited Cell Viability in Prostate Cancer Cells. To examine the effect of phloretin on cell viability, PCa cells (including LNCaP, CWR22Rv1, PC-3, and DU145 cells) and normal prostate epithelial cells (WPMY-1) were cultured and treated with different concentrations of phloretin $(0,20,50$, and $100 \mu \mathrm{M})$ for $24 \mathrm{~h}$, and then cell morphology and cell viability were photographed by microscopy and determined by MTT and CCK-8 assays. As shown in Figure 2(a), phloretin significantly induced PCa cell morphological changes (such as obviously shrunken, rounded, and even floated) in a dose-dependent manner, whereas no distinctly changes in normal WPMY-1 cells even treated with $100 \mu \mathrm{M}$ of phloretin. MTT and CCK8 assays showed that phloretin inhibited the viability of $\mathrm{PCa}$ cells in a dose-dependent manner, while there is almost no effect on WPMY-1 cells (Figures 2(b) and 2(c)). All the results indicated that phloretin could inhibit cell growth, while there is no obvious effect on normal prostate cells.

3.2. Phloretin Induced Cell Cycle Arrest and Apoptosis in PCa Cells. LNCaP and PC-3 cells were cultured and treated with the different concentrations of phloretin $(0,20,50$, and $100 \mu \mathrm{M})$. After $24 \mathrm{~h}$, cells were treated for flow cytometry analysis and DAPI staining assay. As shown in Figure 3(a), phloretin treatment induced cell apoptosis in a concentration-dependent manner in both LNCaP and PC-3 cells. DAPI staining assay showed that phloretin treatment induced cell shrivelled to rupture and nuclearly broken into pieces in a concentration-dependent manner (pointed by the white arrow) and resulted in cell apoptosis in LNCaP and PC-3 cells (Figure 3(c)). In addition, cell cycle analysis demonstrated that phloretin treatment induced cell cycle arrest in G2/M phase in a concentration-dependent manner in both cell lines (Figure 3(b)).

Western blot data further identified that phloretin treatment in LNCaP and PC-3 cells decreased the protein levels of Cyclin B1, XIAP, and Bcl-2, while increased the protein levels of c-Caspase 3 (cleaved Caspase 3), c-PARP-1 (cleaved PARP-1), c-Caspase 8 (cleaved Caspase 8), and c-Caspase 9 (cleaved Caspase 9). The change degrees were all in a phloretin dose-dependent manner (Figure 3(d)). Although phloretin increased the level of BAX in a dose-dependent manner only in LNCaP cells (no changes in PC-3 cells), the $\mathrm{BAX} / \mathrm{Bcl}-2$ ratios in both cell lines were upregulated by phloretin in a dose-dependent manner. Furthermore, we found that phloretin treatment did not change the protein level of p53 in LNCaP cells (undetectable in PC-3 cells) (Figure 3(d)), suggesting that phloretin-induced PCa cell apoptosis was p53 independent.

3.3. Phloretin Inhibited the Activation of EGFR and Its Downstream PI3K/AKT and MEK/ERK Pathways and Then Decreased the Activities of GSK-3 $\beta$ and Sp1. In exploring the molecular mechanism of phloretin-induced cell growth inhibition, cell cycle arrest, and apoptosis in PCa cells, we found that phloretin treatment substantially downregulated the autophosphorylation levels of EGFR at Y1173, but not the total protein level of EGFR (Figure 4(a)), suggesting the activity of EGFR was inhibited by phloretin (it is the same as isorhapontigenin treatment in PCa cells we reported previously [35]). As the downstream of EGFR, the PI3K/AKT and MEK/ERK1/2 pathways have been reported to play the crucial roles in regulating cell survival, growth, migration, and invasion $[20,21]$. From the western blot data, we also found that phloretin downregulated the levels of $\mathrm{p}-\mathrm{PI} 3 \mathrm{~K}, \mathrm{p}$ AKT(S473), p-AKT(T308), p-C-RAF, p-MEK, and pERK1/2 in a concentration-dependent manner, while there is almost no effect on the total protein levels of PI3K, AKT, RAF, MEK1/2, and ERK1/2 in PCa cells (Figures 4(a) and 4(b)).

GSK $3 \beta$ is a downstream target of AKT and inactivated by AKT-induced phosphorylation of GSK $3 \beta$ proteins at Ser9 [25]. Our results showed that phloretin treatment in $\mathrm{PCa}$ cells decreased the phosphorylation level of GSK3 $\beta$ at Ser9 in a concentration-dependent manner, while the total protein level of GSK $3 \beta$ unchanged (Figure $4(\mathrm{c})$ ), suggesting that phloretin increased the activity of GSK $3 \beta$ via inhibiting the PI3K/AKT pathway.

As reported, the activity of $\mathrm{Sp} 1$ was regulated by $\mathrm{AKT}$, ERK1/2, and GSK3 $\beta$, respectively. AKT could upregulate the expression of $S p 1$ gene $[36,37]$, ERK1/2 could phosphorylate Sp1 at Thr453/Thr739 and then facilitate its binding to promoters of the targeted genes $[26,27]$, and GSK $3 \beta$ could induce the degradation of Sp1 proteins $[24,25]$. Here, phloretin treatment in $\mathrm{LNCaP}$ and PC-3 cells decreased the total protein level of Sp1 and the phosphorylation levels of Sp1 at Thr453/Thr739 in a concentration-dependent manner, and the quantification data of the ratios of $\mathrm{p}-\mathrm{Sp} 1 / \mathrm{Sp} 1$ (including p-Sp1 at both T453 and T739) further demonstrated that phloretin-induced decrease of $\mathrm{p}-\mathrm{Sp} 1$ (T453/T739) levels was also concentration dependent (Figure 4(c)). Therefore, phloretin-induced inhibition of AKT and ERK1/2 inevitably inhibited $S p 1$ expression, decreased the phosphorylation of Sp1(T453/T739) and GSK3 $\beta$ (S9), induced Sp1 degradation, and finally decreased $\mathrm{Sp} 1$ activity and impaired Sp1 binding to the promoters of its downstream genes.

Together, phloretin inhibited AKT and ERK1/2 and activated GSK $3 \beta$, and subsequently decreased the transcriptional activity of Sp1 by downregulating the expression of Sp1 gene, inducing the degradation of Sp1 and decreasing Sp1-binding to the promoters of its target genes in PCa cells.

3.4. Phloretin Decreased the Expression of Sp1-Targeted Genes in $\mathrm{PCa}$ Cells. As a transcription factor, $\mathrm{Sp} 1$ could regulate the expression of multiple genes, including Sp3/4, XIAP, VEGF, 

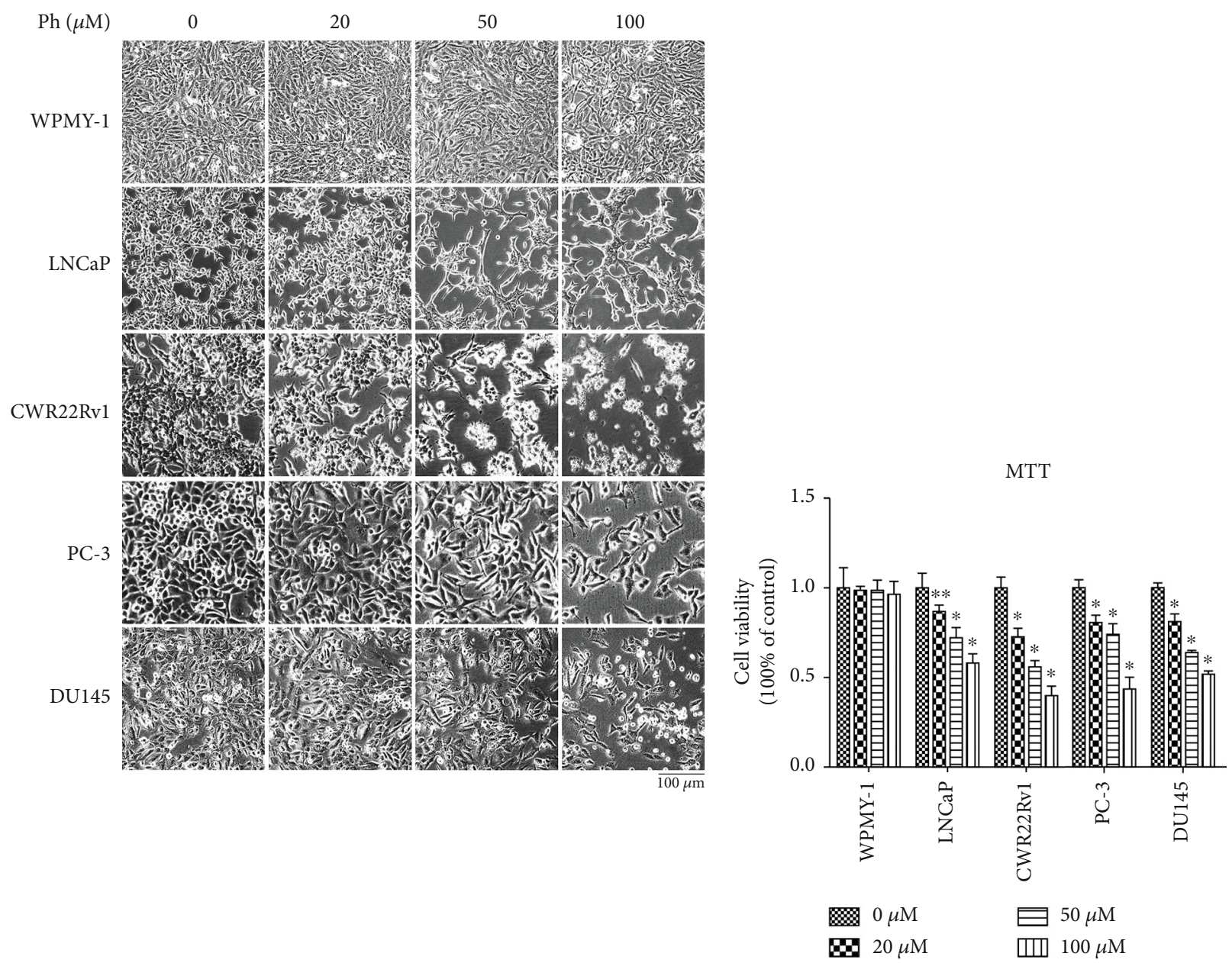

(a)

(b)

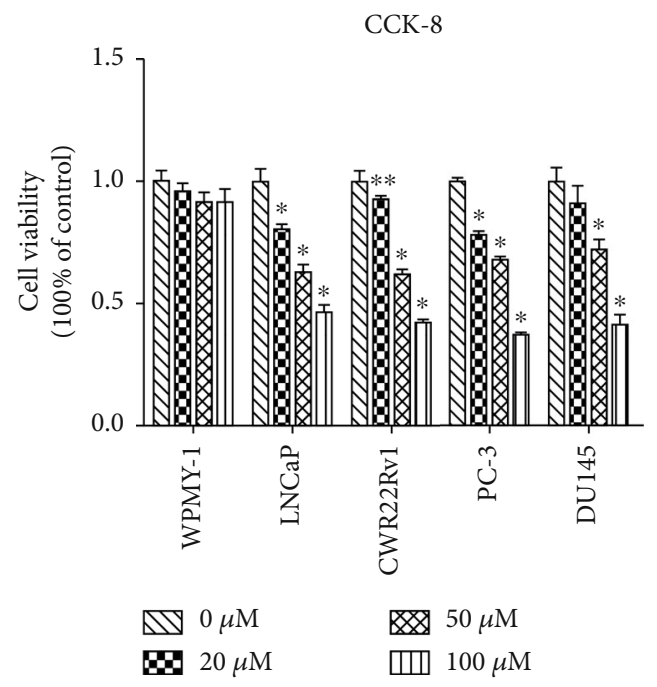

(c)

FIGURE 2: Phloretin treatment induced morphological changes and decreased cell viability in prostate cancer cells. (a) After treating with different concentrations of phloretin $(0,20,50$, and $100 \mu \mathrm{M})$ in WPMY-1, LNCaP, CWR22Rv1, PC-3, and DU145 cells $\left(2 \times 10^{5}\right.$ cells/well) for $24 \mathrm{~h}$, cell morphological changes were observed and photographed with microscope (Nikon microscope, Japan) under 10x magnification. (b, c) WPMY-1, LNCaP, CWR22Rv1, PC-3, and DU145 cells were treated with different concentrations of phloretin (0, 20, 50 , and $100 \mu \mathrm{M})$ for $24 \mathrm{~h}$, and then cells were harvested for MTT and CCK- 8 assays, respectively. The percentages of cell viabilities were calculated by comparing with control samples. ${ }^{*} P<0.01,{ }^{* *} P<0.05$. 


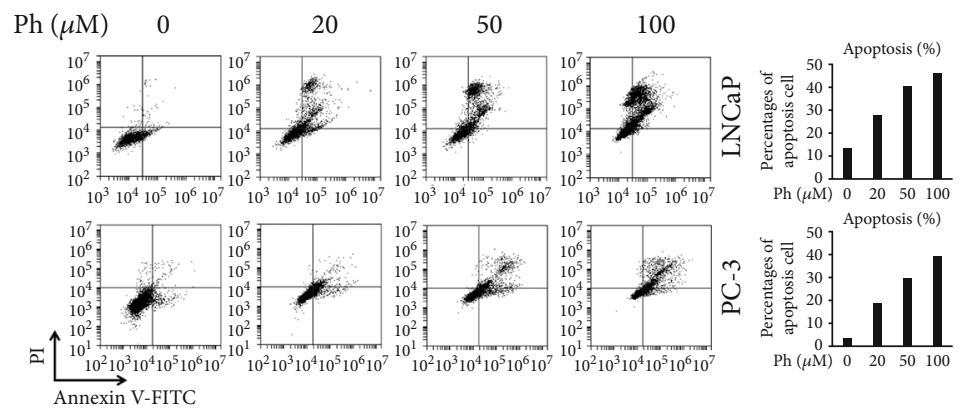

(a)

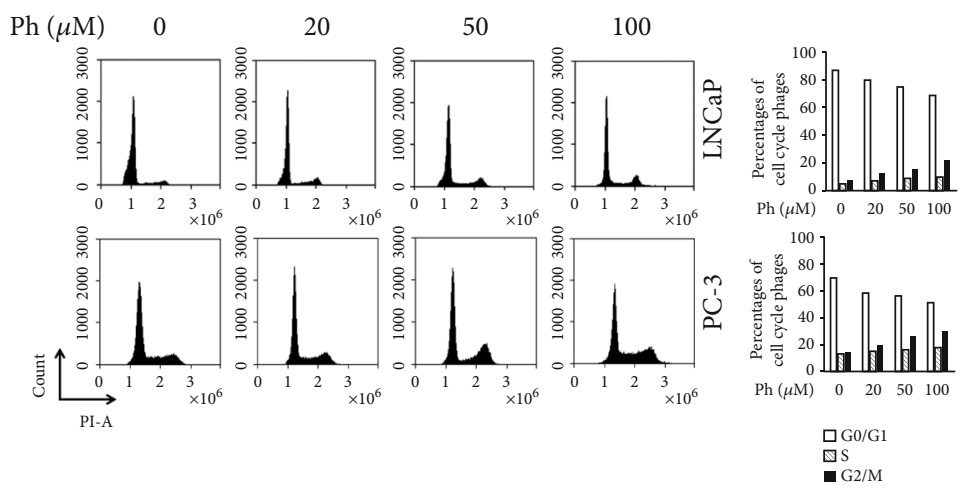

(b)
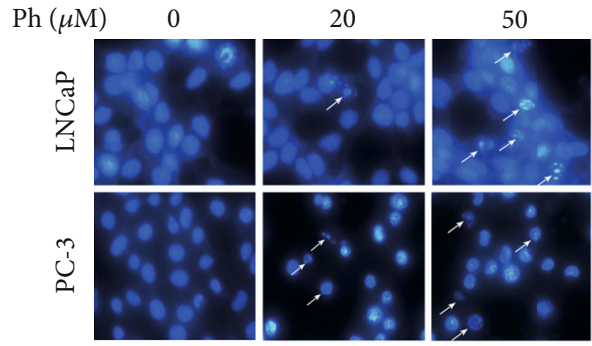

(c)
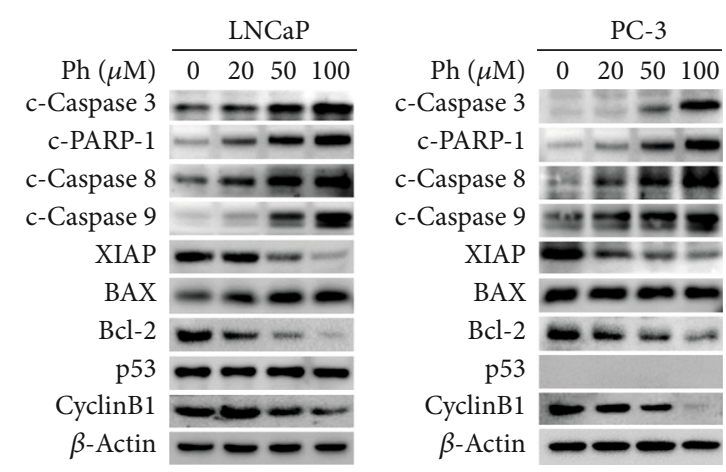

(d)

Figure 3: Phloretin induced cell apoptosis and cell cycle arrest in PCa cells. (a, b) LNCaP and PC-3 cells were treated with phloretin (0, 20, 50, and $100 \mu \mathrm{M}$ ) for $24 \mathrm{~h}$ and then harvested for flow cytometry analysis to check cell cycle and apoptosis. Percentages of cell cycle phages and apoptosis were quantified, respectively. (c) LNCaP and PC-3 cells were treated with phloretin ( 0 , 20, 50, and $100 \mu \mathrm{M})$ for $24 \mathrm{~h}$, and then cells were stained by DAPI, observed, and photographed with fluorescence microscope under 40x magnification. (d) LNCaP and PC-3 cells were treated with phloretin $(0,20,50$, and $100 \mu \mathrm{M})$ and then harvested for western blot assay to check the protein levels of c-Caspase 3, c-PARP-1, c-Caspase 8, c-Caspase 9, Bcl-2, BAX, XIAP, p53, Cyclin B1, and $\beta$-actin (loading control).

Survivin, Cyclin D1, AR, and Sp1 itself [16-19, 32, 38-41]. To identify the effect of phloretin on these Sp1-targeted genes, LNCaP and PC-3 cells were cultured and treated with different concentrations of phloretin $(0,20,50$, and $100 \mu \mathrm{M})$. After $24 \mathrm{~h}$, cells were harvested for both western blot assay and RT-PCR assay as indicated in Figures 5(a) and 5(b). The results showed that phloretin treatment in LNCaP and PC-3 cells decreased the expression of $S p 1$ and its target genes (including Sp3/4, XIAP, VEGF, Survivin, Cyclin $D 1$, and $A R$ ) in both protein and mRNA levels in a concentration-dependent manner (Figures 5(a) and 5(b)). Further, the confocal data showed that phloretin treatment in LNCaP and PC-3 cells obviously decreased the protein levels of $\mathrm{Sp} 1$ and $\mathrm{Sp} 3 / 4$ in a phloretin concentrationdependent manner (Figure 5(c)).

Additionally, data of dual luciferase reporter assay also showed that phloretin treatment decreased the luciferase activities in PC-3 cells transfected with plasmids pSp1(751/-20)-Luc, pSp3(-417/-38)-Luc, pVEGF(-2018/+50)-Luc, and pSurvivin(-269/-39)-Luc in a concentration-dependent manner (Figure 5(d)).

These results demonstrated that phloretin treatment in PCa cells downregulated the expression of Sp1-targeted genes by decreasing the transcription activity of Sp1. 


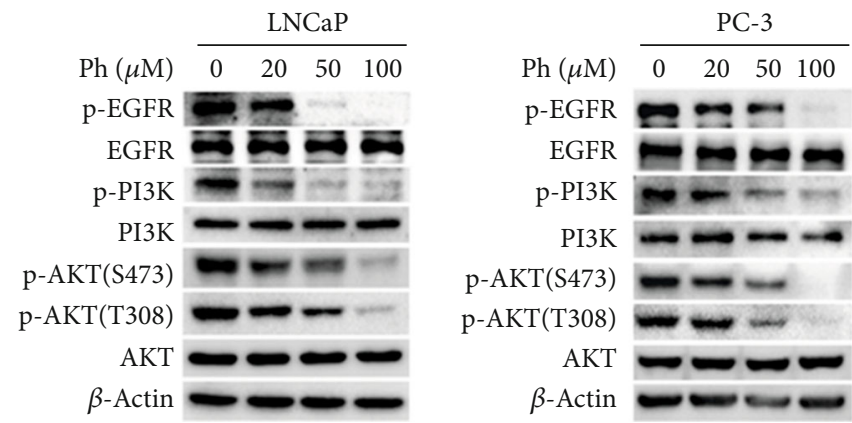

(a)

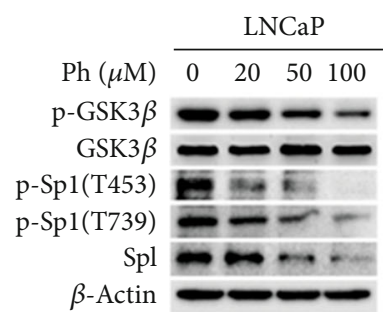

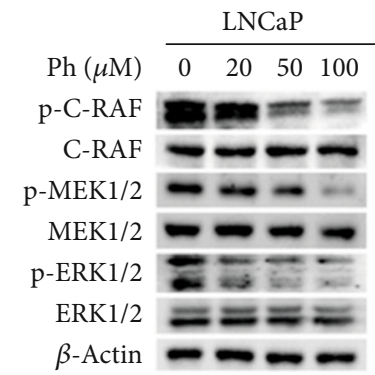

(b)

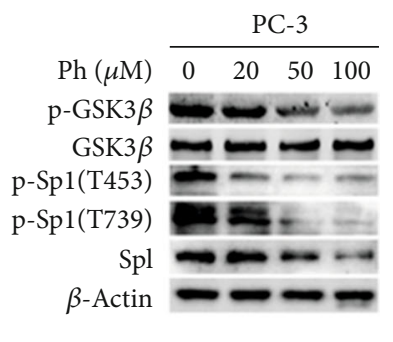

(c)
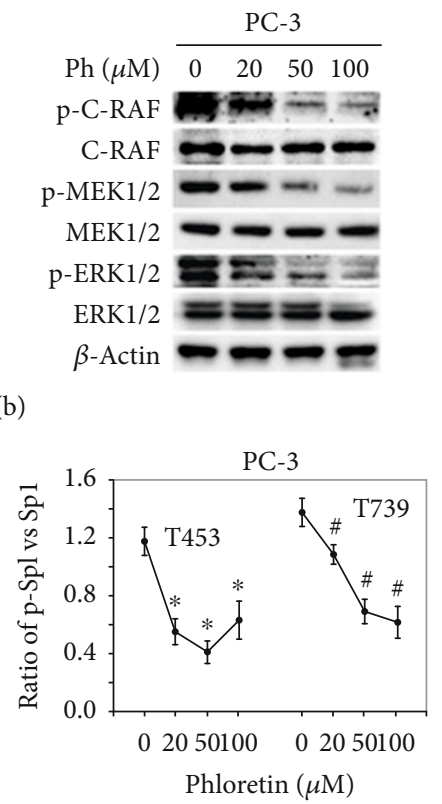

FIGURE 4: Phloretin inhibited the activities of EGFR and its downstream PI3K/AKT, MEK/ERK, and GSK3 $\beta$ pathways. (a) LNCaP and PC-3 cells were incubated with phloretin $(0,20,50$, and $100 \mu \mathrm{M})$ for $24 \mathrm{~h}$ and then harvested for western blot assays to check the protein levels of pEGFR(Y1173), EGFR, p-PI3K, PI3K, p-AKT(S473), p-AKT(T308), AKT, p-GSK3 $\beta$ (S9), GSK3 $\beta$, and $\beta$-actin (loading control). (b) LNCaP and PC-3 cells were treated with phloretin as above and then harvested for western blot assays to check the protein levels of p-CRAF(S338), C-RAF, p-MEK(S217/S221), MEK, p-ERK1/2(T202/Y204), ERK1/2, and $\beta$-actin (loading control). (c) LNCaP and PC-3 cells were treated with phloretin and then harvested for western blot assay to check the protein levels of p-Sp1(T453), p-Sp1(T739), Sp1, and $\beta$-actin (loading control); the ratio of $\mathrm{p}$-Sp1 levels vs. total $\mathrm{Sp} 1$ levels was quantified using ImageJ software. ${ }^{*} P<0.01 ;{ }^{* *} P<0.05 ;{ }^{*} P<0.01$.

3.5. Phloretin Decreased the Level of Sp1 by Increasing the Degradation of Sp1 Protein in PCa Cells. To identify the degradation of Sp1 protein by phloretin-induced inhibition of PI3K/AKT and activation of GSK $3 \beta, \mathrm{LNCaP}$ and PC- 3 cells were cultured and treated with $\mathrm{CHX}(10 \mu \mathrm{g} / \mathrm{ml})$ and/or phloretin $(50 \mu \mathrm{M})$ for different time as indicated Figure 6(a), and then cells were harvested for western blot assay. The data showed that treatment with CHX alone caused the decrease of $\mathrm{Sp} 1$ protein level in a time-dependent manner; cotreatment with $\mathrm{CHX}$ and phloretin resulted in a more decrease of Sp1 protein level. The quantification data also demonstrated that the levels of Sp1 in CHX-treated cells were further decreased by phloretin treatment in a time-dependent manner, suggesting that phloretin could induce the degradation of Sp1 proteins. In addition, the Sp1-targeted genes Sp3/4 were also decreased with the downregulation of Sp1 (Figure 6(a)).

To further identify phloretin-induced degradation of Sp1, LNCaP and PC-3 cells were cultured and treated with phloretin $(50 \mu \mathrm{M})$ and/or MG132 $(10 \mu \mathrm{M})$ as indicated in Figure 6(b) and then harvested for western blot assay. Our data showed that phloretin-induced decrease of Sp1 and Sp3/4 could be partially rescued by cotreated MG132 (Figure 6(b)). Moreover, dual-luciferase assay showed that MG132 treatment could also partially reverse the phloretininduced decrease of the luciferase activities in PC-3 cells transfected with pSp1(-751/-20)-Luc, Sp3(-417/-38)-Luc, VEGF(-2018/+50)-Luc, and Survivin(-269/-39)-Luc, respec- tively (Figures 6(b) and 6(c)). It demonstrated that phloretin induced the protein level decrease of Sp1 and its target genes were not only decreasing Sp1 gene expression and Sp1 mRNA translation but also inducing Sp1 protein degradation.

3.6. Phloretin Decreased the Sp1 Levels by Decreasing Cytoplasmic Distribution of Nucleolin and Then Decreasing the Binding of Nucleolin to $5^{\prime}$-UTR of Sp 1 mRNA. To identify the effect of nucleolin on phloretin-induced decrease of Sp1 proteins in PCa cells, LNCaP and PC-3 cells were transfected with expression plasmid of nucleolin and treated with phloretin as indicated in Figure 1(a) and then checked the protein levels of Sp1 and its downstream proteins, including VEGF and Cyclin D1. From the experimental data, we found that overexpression of nucleolin upregulated the protein levels of Sp1 and its downstream proteins in both LNCaP and PC-3 cells, and phloretin treatment in PCa cells obviously suppressed nucleolin-induced upregulation of protein levels of Sp1 and its targeted proteins (Figure 1(a)).

It is reported that nucleolin could be recruited to the $5^{\prime}$-UTR of Sp1 mRNA in the cytoplasm as an IRES (internal ribosomal entry site, nucleolin binding site is $+1 / 250$ bp of $5^{\prime}$-UTR of Sp1 mRNA) transacting factor to enhance the translation of Sp1 mRNA during lung cancer formation [31], and PI3K/AKTinduced phosphorylation of nucleolin at Thr76 and Thr84 promoted nucleolin translocation from the nucleus to the cytoplasm in the cells of colorectal carcinoma [30]. To identify the effect of 


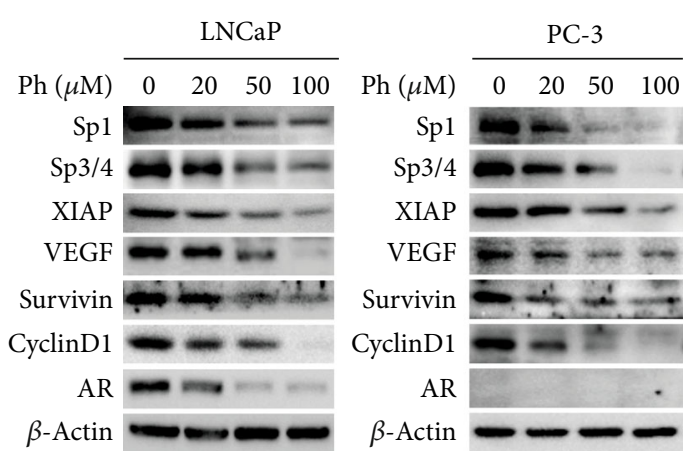

(a)

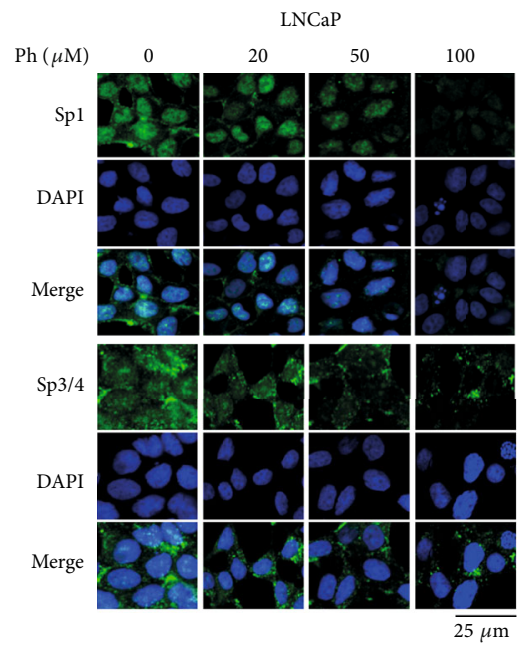

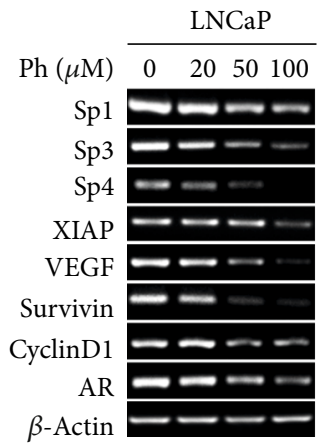

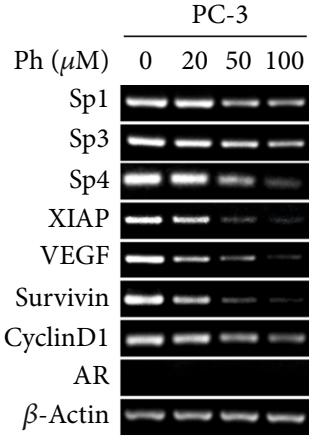

(b)

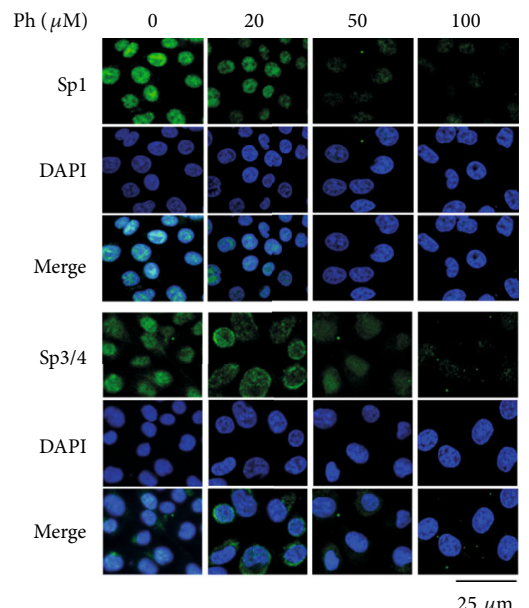

(c)
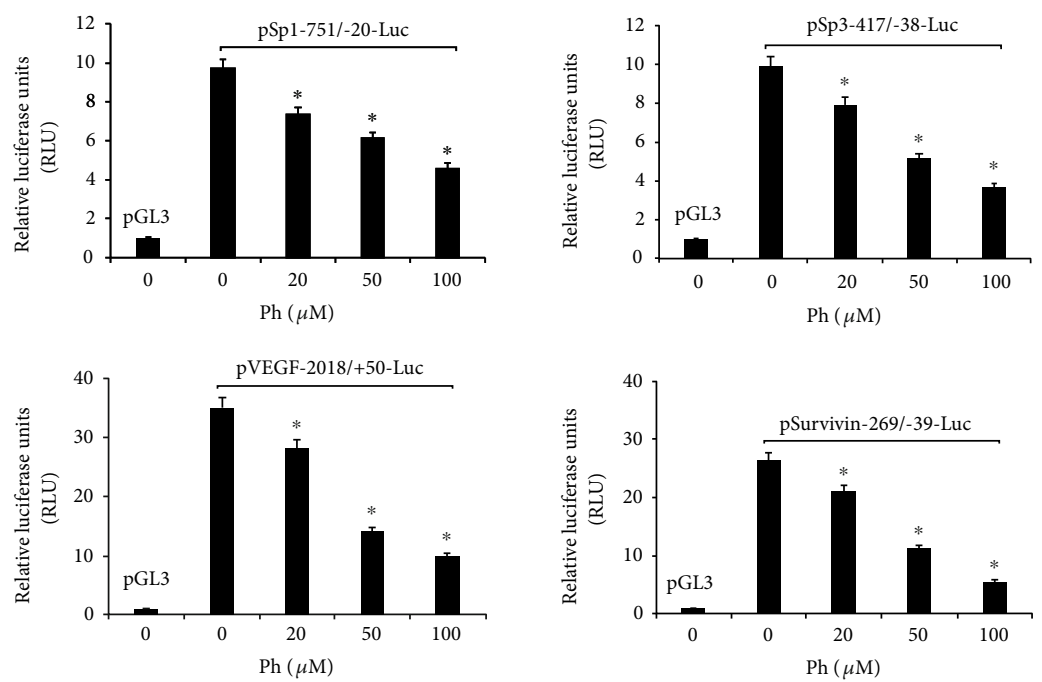

(d)

Figure 5: Phloretin decreased the expression of Sp1-targeted genes by downregulating Sp1 levels in PCa cells. (a, b) LNCaP and PC-3 cells were treated with phloretin $(0,20,50$, and $100 \mu \mathrm{M})$ for $24 \mathrm{~h}$ and then harvested for western blot (a) and RT-PCR (b) assays to check the expressions of $S p 1$ and its target genes (including Sp3/4, XIAP, VEGF, Survivin, Cyclin D1, and AR) in both mRNA and protein levels ( $\beta$ actin as control). (c) LNCaP and PC-3 cells were cultured in 12-well plates with cover slips and then treated with phloretin (0, 20, 50, and $100 \mu \mathrm{M}$ ) for $24 \mathrm{~h}$. Cells grown on cover slips were treated for immunofluorescent confocal analysis with Sp1 and Sp3/4 antibodies (the cell nucleus was stained with DAPI). (d) PC-3 cells were transfected with pSp1-751/-20-Luc, pSp3-417/-38-Luc, pVEGF-2018/+50-Luc, pSurvivin-269/-39-Luc, and pGL3-basic and treated with phloretin $(0,20,50$, and $100 \mu \mathrm{M})$, and then luciferase activities were measured by using the Dual-Luciferase Reporter Assay Kit. The relative luciferase units (RLU) were calculated. ${ }^{*} P<0.01$. 


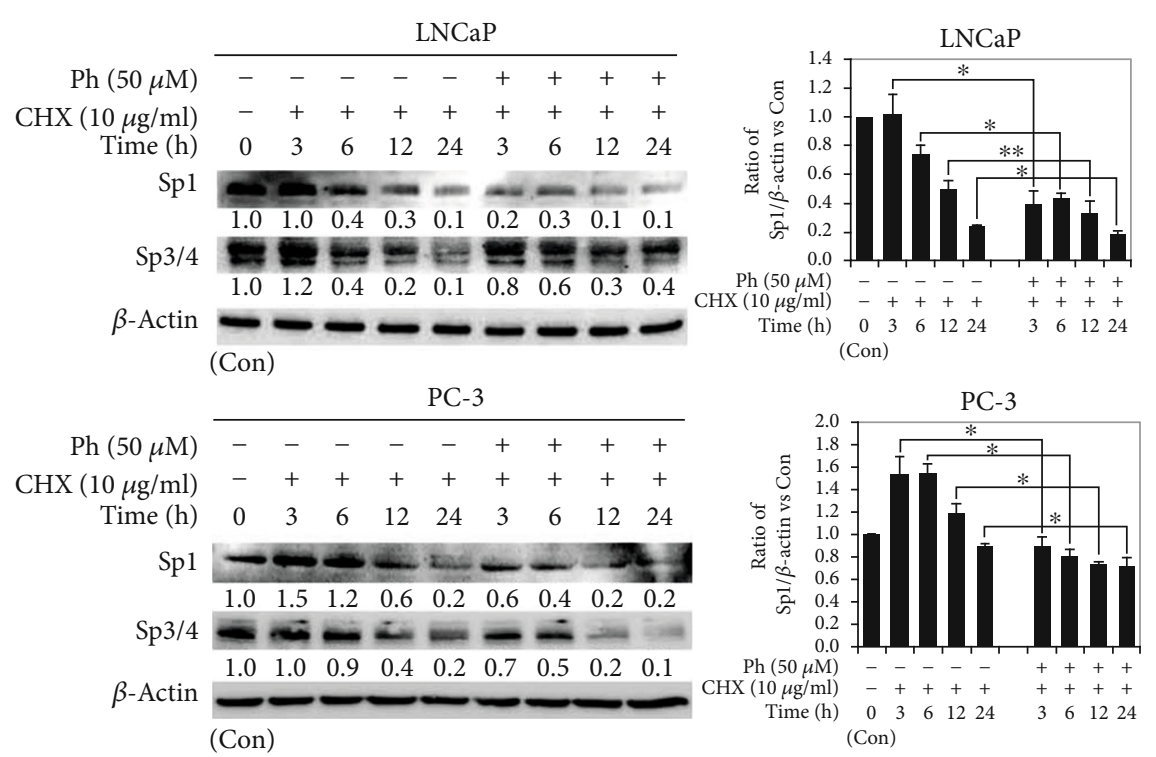

(a)

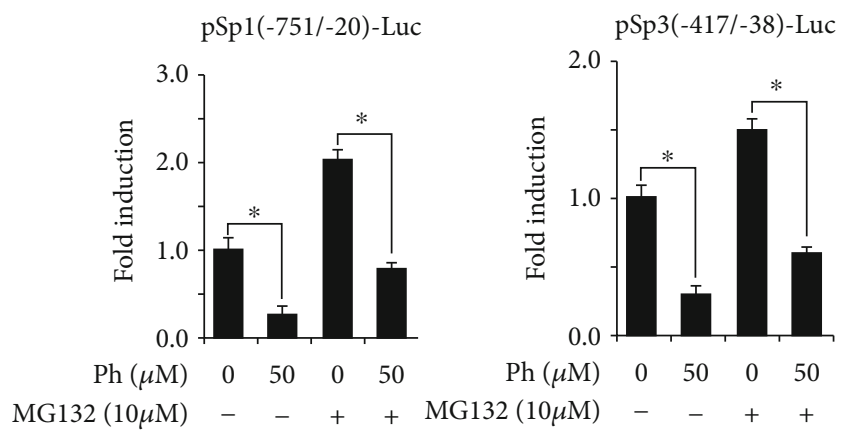

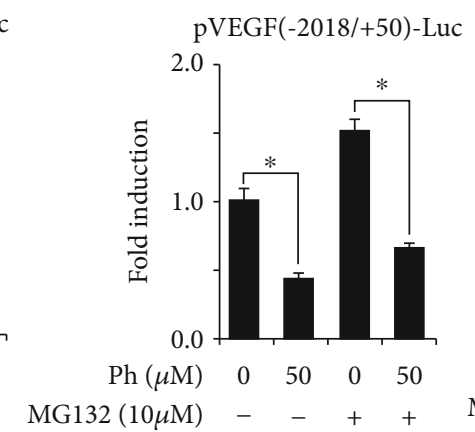

(c)
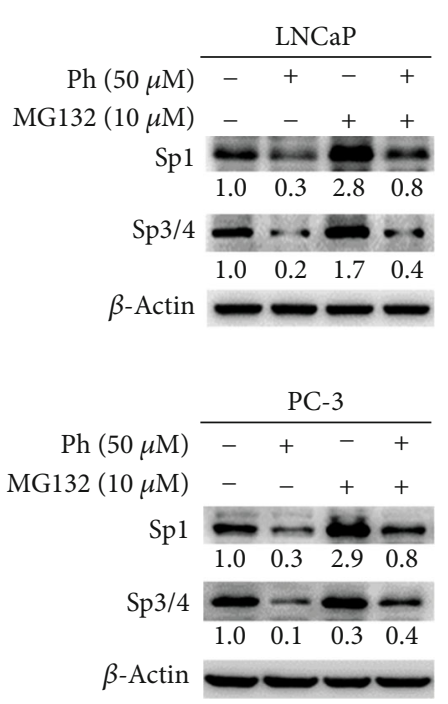

(b)

FIgure 6: Phloretin induced the degradation of Sp1 protein in PCa cells. (a) Cells were treated with $10 \mu \mathrm{g} / \mathrm{ml} \mathrm{CHX} \mathrm{alone} \mathrm{or} \mathrm{cotreated} \mathrm{with}$ $10 \mu \mathrm{g} / \mathrm{ml} \mathrm{CHX}$ and $50 \mu \mathrm{M}$ phloretin (CHX pretreated for $30 \mathrm{~min}$ ) for western blot assays to detect the protein levels of Sp1 and Sp3/4. The quantification: first, the densities of bands of Sp1 and $\beta$-actin were quantified using ImageJ software, and the ratios of Sp1/ $\beta$-actin (the Sp1 and $\beta$-actin with no treatment of phloretin and CHX as control) were calculated; second, the ratios of Sp1/ $\beta$-actin vs. Con were obtained by using the values of Sp1/ $\beta$-actin vs. the value of control Sp1/ $\beta$-actin (control Sp1/ $\beta$-actin vs. control Sp1/ $\beta$-actin as 1 ). (b) Cells were treated with phloretin $(50 \mu \mathrm{M})$ and/or MG132 $(10 \mu \mathrm{M})$, and then cells were harvested for western blotting assay to detect the protein levels of Sp1 and Sp3/4. All western blotting assays used $\beta$-actin as loading control. (c) PC-3 cells were transfected with the various luciferase constructs and treated with phloretin $(50 \mu \mathrm{M})$ or MG132 $(10 \mu \mathrm{M})$ alone, or cotreated with phloretin $(50 \mu \mathrm{M})$ and $\mathrm{MG} 132$ $(10 \mu \mathrm{M})$, and then dual-luciferase activities (Firefly and Renilla) were measured. The fold inductions of luciferases were calculated by using relative luciferases (the relative luciferase of control as 1 ). ${ }^{*} P<0.01 ;{ }^{* *} P<0.05$. Con: control.

phloretin on the phosphorylation of nucleolin at Thr76 and Thr84 and the distribution of nucleolin in the nucleus and the cytoplasm, LNCaP and PC-3 cells were incubated with $50 \mu \mathrm{M}$ or different concentrations of phloretin (as indicated in Figures 1(b) and 1(c)) for $24 \mathrm{~h}$. Then, cells were harvested for nucleus/cytoplasm separation and/or western blot assays to detect the nucleus/cytoplasm distribution and phosphorylation (Thr76/Thr84) levels of nucleolin. From the results, we found that the protein levels of nucleolin were decreased in cytoplasm and increased in the nucleus with the treatment of phloretin (Figure 1(b)). Levels of p-Nucleolin(Thr76) and p-Nucleolin(Thr84) were distinctly decreased by the treated phloretin in a concentration-dependent manner, while the total protein levels of nucleolin were almost not changed in LNCaP and PC-3 cells (Figure 1(c)).
In addition, RNA-IP experiment was employed to identify the effect of phloretin on nucleolin binding to $5^{\prime}$-UTR of Sp1 mRNA. LNCaP and PC-3 cells (treated with different concentrations of phloretin as indicated in Figure 1(d)) were harvested for direct RT-PCR of $5^{\prime}$-UTR of Sp1 mRNA and for RNA-IP with IgG/nucleolin antibodies. Then, the RNAs of IP were also extracted for RT-PCR of $5^{\prime}$-UTR of Sp1 mRNA. The direct RT-PCR data showed that the mRNA levels of $\beta$-actin (as internal control) were not changed with the treatment of phloretin, while the total levels of $5^{\prime}$-UTR of $\mathrm{Sp} 1 \mathrm{mRNA}$ (as input) were decreased with the treatment of phloretin in a concentration-dependent manner in both PCa cell lines (Figure 1(d)). The RNA-IP experimental data showed that the levels of nucleolin-bound $5^{\prime}$-UTR of Sp1 


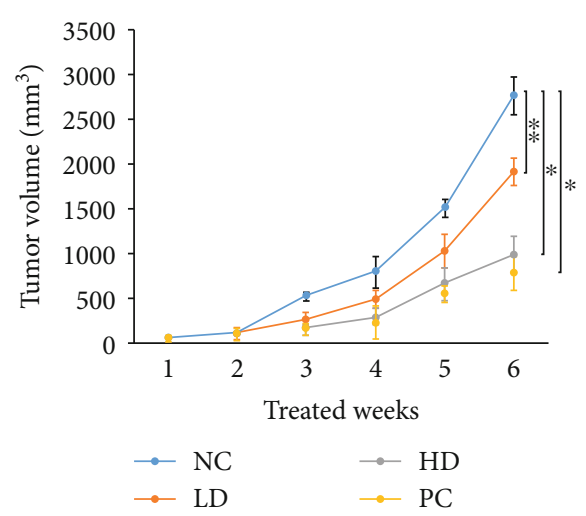

(a)

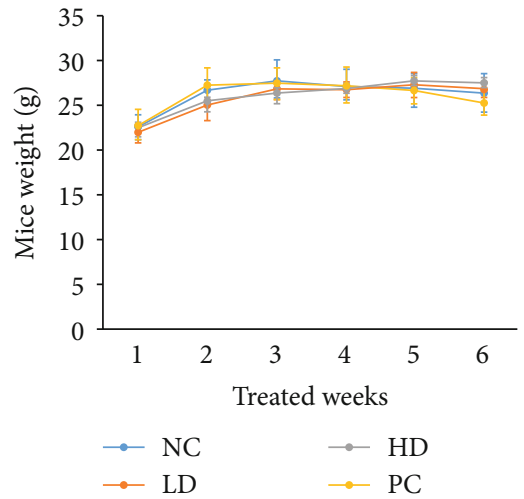

(b)

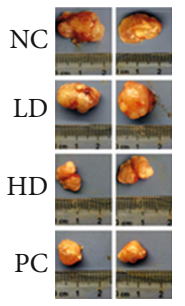

(c)

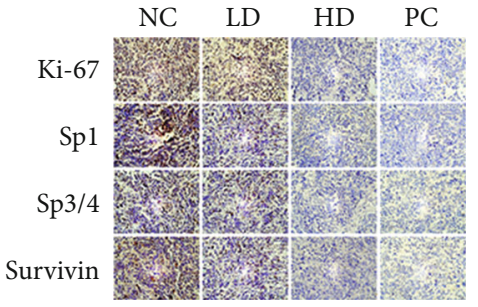

(d)

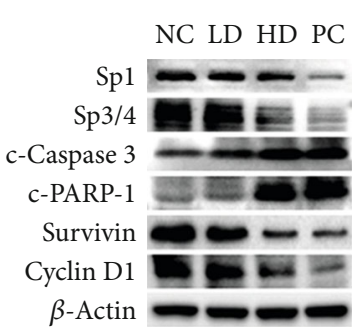

(e)

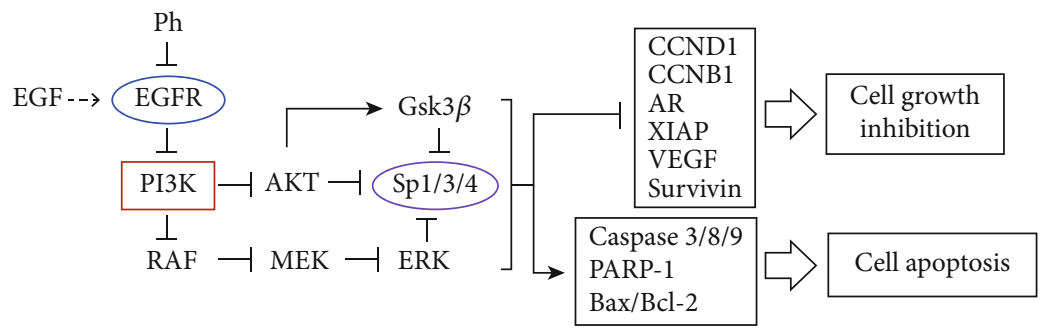

(f)

Figure 7: Phloretin suppressed PC-3 cell xenograft tumor growth and induced PC-3 cell apoptosis in nude mice. The nude mice with PC-3 cell xenograft tumors in the subcutaneous tissue $\left(\sim 30-50 \mathrm{~mm}^{3}\right)$ were treated intraperitoneally with phloretin (low-dose $10 \mathrm{mg} / \mathrm{kg}$ and highdose $50 \mathrm{mg} / \mathrm{kg}$ ), 1× PBS (as negative control), and 5-FU (as positive control) every two days for 6 weeks. (a) Tumor volumes of the PBS group (negative control), the low-dose phloretin group (low $\mathrm{Ph}$ ), the high-dose phloretin group (high $\mathrm{Ph}$ ), and the 5-FU group (positive control) were measured every week, and the average tumor volumes of each group were calculated. ${ }^{*} P<0.01,{ }^{* *} P<0.05$. (b) Mouse weights were measured every week and the average mouse weights of four groups were calculated. (c) At the end of the experiment, mice were sacrificed, and subcutaneous tumors were isolated and photographed. (d) The protein levels of Ki-67, Sp1, Sp3/4, and Survivin in tumor tissues were checked by using IHC assay. (e) The protein levels of Sp1, Sp3/4, c-Caspase 3, c-PARP-1, Survivin, and Cyclin D1 in tumor tissues were determined by using western blot assay. (f) Schematic diagram of signal pathways in phloretin-induced cell growth inhibition and apoptosis in human prostate cancer cells. NC: negative control; LD: low dose; HD: high dose; PC: positive control.

mRNA were obviously decreased with the treatment of phloretin in a concentration-dependent manner in both PCa cell lines, and the decreasing degree was a little higher than that of input of $5^{\prime}$-UTR (Figure $1(\mathrm{~d})$ ). Besides, no RTPCR products were detected in the negative control samples of RNA-IP with IgG (Figure 1(d)).

These results suggested that phloretin treatment in PCa cells decreased the levels of cytoplasmic nucleolin via downregulating the phosphorylation levels of nucleolin at Thr76 and Thr84 and then resulted in the reduction of nucleolin binding to $5^{\prime}$-UTR of Sp1 mRNA in the cytoplasm. It might inevitably lead to the decrease of nucleolin-induced Sp1 mRNA translation.
3.7. Phloretin Suppressed Tumor Growth and Induced Apoptosis of Prostate Cancer Cells In Vivo. To investigate the efficacy of phloretin on prostate cancer cells in vivo, subcutaneous xenotransplanted tumor models of PC-3 cell in nude mice were established to evaluate the inhibition of tumor growth by phloretin treatment. Compared with the negative control group, our results showed that phloretin treatment in vivo inhibited growth of the transplanted prostate tumors in a time-dependent manner in both the highdose and low-dose phloretin-treated groups, while the body weights of mice had no significant changes in all groups (Figures 7(a) and 7(b)). At the end of experiments, the tumor volumes of mice in the high-dose (HD) group were much smaller than those in both the negative control (NC) and 
low-dose (LD) groups and almost the same as those in the positive control (PC) group (Figures 7 (a) and 7(c)).

Immunohistochemistry (IHC) data showed that the levels of Ki-67 (marker of cell proliferation), Sp1, Sp3/4, and Survivin in the cells of PC-3-transplanted tumor tissues were all decreased with the treatment of phloretin, and these protein levels in the tumor cells of the HD group were almost the same as those of the PC group (5-FU treatment) (Figure $7(\mathrm{~d})$ ). In addition, the western blot data of PC-3transplanted tumor tissues demonstrated that the protein levels of Sp1, Sp3/4, Survivin, and Cyclin D1 were decreased, while the protein levels of c-Caspase 3 and c-PARP-1 were increased in the $\mathrm{HD}$ and $\mathrm{PC}$ groups (compared with the NC and LD groups) (Figure 7(e)).

These results demonstrated that phloretin treatment could also inhibit PC-3 cell growth and induce PC-3 cell apoptosis in vivo, and the high-dose phloretin had a greater inhibition efficacy on the growth of PCa cell-transplanted tumors by comparing with low-dose phloretin in vivo.

\section{Discussion}

Phloretin has been recently attracted extensive interest and extensively studied in treating many diseases including in anticancer research. Phloretin could induce apoptosis of many types of cancer cells in vitro and inhibit growth of the transplanted tumors of multiple human cancer cell lines in vivo $[5,7,42]$. However, the molecular mechanism of the anticancer effect of phloretin in prostate cancer remained unclear. In this study, we reported that phloretin could inhibit the activation of EGFR and its downstream signal pathways, including the PI3K/AKT, MEK/ERK1/2, and GSK3 $\beta$ pathways. Inhibition of these pathways further inhibited the activation of Sp1 and subsequently resulted in the downregulation of $\mathrm{Sp} 3 / 4$ proteins, cell growth, and antiapoptosis-related proteins (including Cyclin D1, Cyclin B1, Bcl-2, Survivin, AR, VEGF, and XIAP) and the upregulation of cell apoptosis-related proteins (including c-Caspase 3, c-Caspase 8, c-Caspase 9, and c-PARP-1), and finally resulted in cell growth inhibition and apoptosis in prostate cancer cells both in vitro and in vivo (Figure $7(\mathrm{f})$ ).

Usually, p53 is the key protein in cell growth inhibition and cell apoptosis promotion involved in the inhibition of pathways that related to cell cycle and the activation of pathways that related to cell apoptosis $[43,44]$. In current study, the protein levels of p53 were almost not changed in LNCaP cells and almost not detected in PC-3 cells (Figure 3(d)). In addition, the phosphorylation levels of p53(Ser15) in LNCaP cells which related to the activity of p53 protein were decreased with the treatment of phloretin (data not shown). It indicated that p53 was not the key factor in phloretininduced cell growth inhibition and apoptosis in prostate cancer cells. Thus, our experimental results indicated that phloretin-induced cell apoptosis was in a p53-independent manner in PCa cells. Based on the capability of Sp1 in modulating the expression of Cyclin B1 gene [45], we could conclude that phloretin-induced downregulation of cyclin B1 and cell cycle arrest at G2/M phase in PCa cells was not via the $\mathrm{p} 53 /$ cyclin B1 pathway, but via the Sp1/cyclin B1 pathway.
Nucleolin, the RNA-binding protein, is involved in mRNA processing including the regulation of mRNA stability and translational efficiency [46]. During lung cancer formation, nucleolin was recruited to the $5^{\prime}$-UTR of Sp1 mRNA to enhance cap-independent translational activity in the cytoplasm. Phosphorylation of nucleolin was also important to increase the distribution of nucleolin protein in the cytoplasm and enhance nucleolin binding to $5^{\prime}$-UTR of Sp1 mRNA [30, 31]. Our results here identified that phloretin treatment in PCa cells downregulated the phosphorylation levels of nucleolin and resulted in the decreased distribution of nucleolin protein in the cytoplasm and reduced nucleolin binding to $5^{\prime}$-UTR of Sp1 mRNA, and finally decreased the translational efficiency of Sp1 mRNA. Of course, more details of the molecular mechanism of the relationship between phloretin and nucleolin needed to be further explored.

Sp1, usually overexpressed in many human tumors and cancer cell lines $[8,9]$, plays an important role in tumorigenesis and cancer progress and is a potential target for development of drugs in cancer chemotherapy [47]. Regulation of Sp1 activity should be an effective strategy for cancer drug screening. As reported, Sp1 is positively regulated by AKT and ERK and negatively regulated by GSK $3 \beta$, and GSK $3 \beta$ is negatively regulated by the PI3K/AKT pathway again [24-27, 36, 37]. Our study demonstrated that phloretin-induced inhibition of Sp1 in PCa cells included at least three pathways: first, phloretin induced inhibition of EGFR/PI3K/AKT and then downregulated expression of $S p 1$ gene (phloretin-EGFR/PI3K/AKT-Sp1 pathway); second, phloretin induced inhibition of EGFR/PI3K/AKT and then decreased the phosphorylation levels of GSK3 $\beta(\mathrm{S} 9)$ and activated GSK $3 \beta$, and finally induced the degradation of Sp1 proteins (by combined with reported results in [48]); and third, phloretin induced inhibition of EGFR/PI3K/AKT and then downregulated the phosphorylation levels of nucleolin(Thr76/Thr84) and might suppress the translation of Sp1 mRNA (by combined with reported results in [31]). Of course, the detailed molecular mechanisms of phloretin in regulating Sps needed to be further studied in the future studies.

In conclusion, phloretin treatment in PCa cells downregulated the protein levels of Sp1 by inhibiting the expression of Spl genes, increasing the degradation of $\mathrm{Sp} 1$ proteins and suppressing the translation of Sp1 mRNAs via inhibiting the activity of EGFR and its downstream pathways, including the PI3K/AKT, MEK/ERK, AKT/GSK3 $\beta$, and AKT/nucleolin pathways, and finally induced cell cycle arrest, cell growth inhibition, and apoptosis in PCa cells by decreasing the levels of cell cycle/growth-related proteins and increasing the levels of cell apoptosis-related proteins. Our study suggested that phloretin had the potential to be a candidate compound to treat the patients with prostate cancer in clinic in the future.

\section{Data Availability}

The data used to support this study are available from the corresponding author upon request. 


\section{Ethical Approval}

All animal experiments involved in this study were approved (Permission No: NL-129-02) by the Ethics Committee of Jiangsu Province Hospital of TCM, Nanjing, China.

\section{Conflicts of Interest}

The authors declare that they have no competing financial or nonfinancial interests.

\section{Authors' Contributions}

Dan Kang and Wenren Zuo contributed equally to this manuscript.

\section{Acknowledgments}

This work was supported by the National Natural Science Foundation of China (NNSFC) (grant nos. 81772732, 81472415 , and 81872104).

\section{References}

[1] R. L. Siegel, K. D. Miller, and A. Jemal, "Cancer statistics, 2020," CA: A Cancer Journal for Clinicians, vol. 70, no. 1, pp. 7-30, 2020.

[2] N. Khan, V. M. Adhami, and H. Mukhtar, "Apoptosis by dietary agents for prevention and treatment of prostate cancer," Endocrine-Related Cancer, vol. 17, no. 1, pp. R39-R52, 2010.

[3] V. Crespy, O. Aprikian, C. Morand et al., "Bioavailability of phloretin and phloridzin in rats," Journal of Nutrition, vol. 131, no. 12, pp. 3227-3230, 2001.

[4] J. B. Fordham, A. Raza Naqvi, and S. Nares, "Leukocyte production of inflammatory mediators is inhibited by the antioxidants phloretin, silymarin, hesperetin, and resveratrol," Mediators of Inflammation, vol. 2014, Article ID 938712, 11 pages, 2014.

[5] Y. Liu, C. Fan, L. Pu et al., "Phloretin induces cell cycle arrest and apoptosis of human glioblastoma cells through the generation of reactive oxygen species," Journal of Neuro-Oncology, vol. 128, no. 2, pp. 217-223, 2016.

[6] K. C. Yang, C. Y. Tsai, Y. J. Wang et al., “Apple polyphenol phloretin potentiates the anticancer actions of paclitaxel through induction of apoptosis in human Hep G2 cells," Molecular Carcinogenesis, vol. 48, no. 5, pp. 420-431, 2009.

[7] J. Min, X. Li, K. Huang et al., "Phloretin induces apoptosis of non-small cell lung carcinoma A549 cells via JNK1/2 and p38 MAPK pathways," Oncology Reports, vol. 34, no. 6, pp. 2871-2879, 2015.

[8] S. Chintharlapalli, S. Papineni, S. K. Ramaiah, and S. Safe, "Betulinic acid inhibits prostate cancer growth through inhibition of specificity protein transcription factors," Cancer Research, vol. 67, no. 6, pp. 2816-2823, 2007.

[9] M. Abdelrahim, R. Smith III, R. Burghardt, and S. Safe, "Role of Sp proteins in regulation of vascular endothelial growth factor expression and proliferation of pancreatic cancer cells," Cancer Research, vol. 64, no. 18, pp. 6740-6749, 2004.

[10] G. Chadalapaka, I. Jutooru, S. Chintharlapalli et al., "Curcumin decreases specificity protein expression in bladder cancer cells," Cancer Research, vol. 68, no. 13, pp. 5345-5354, 2008.
[11] S. U. Mertens-Talcott, S. Chintharlapalli, X. Li, and S. Safe, "The oncogenic microRNA-27a targets genes that regulate specificity protein transcription factors and the G2-M checkpoint in MDA-MB-231 breast cancer cells," Cancer Research, vol. 67, no. 22, pp. 11001-11011, 2007.

[12] S. Chintharlapalli, S. Papineni, P. Lei, S. Pathi, and S. Safe, "Betulinic acid inhibits colon cancer cell and tumor growth and induces proteasome-dependent and -independent downregulation of specificity proteins $(\mathrm{Sp})$ transcription factors," BMC Cancer, vol. 11, no. 1, 2011.

[13] R. Ammendola, M. Mesuraca, T. Russo, and F. Cimino, "Sp1 DNA binding efficiency is highly reduced in nuclear extracts from aged rat tissues," Journal of Biological Chemistry, vol. 267, no. 25, pp. 17944-17948, 1992.

[14] G. S. Adrian, E. Seto, K. S. Fischbach et al., "YY1 and Spl transcription factors bind the human transferrin gene in an age-related manner," The Journals of Gerontology Series A: Biological Sciences and Medical Sciences, vol. 51A, no. 1, pp. B66-B75, 1996.

[15] J.-E. Oh, J.-A. Han, and E. S. Hwang, "Downregulation of transcription factor, Sp1, during cellular senescence," Biochemical and Biophysical Research Communications, vol. 353, no. 1, pp. 86-91, 2007.

[16] Y. Fang, Y. Yu, Q. Hou et al., "The Chinese herb isolate isorhapontigenin induces apoptosis in human cancer cells by down-regulating overexpression of antiapoptotic protein XIAP," Journal of Biological Chemistry, vol. 287, no. 42, pp. 35234-35243, 2012.

[17] M. Verras, J. Lee, H. Xue, T. H. Li, Y. Wang, and Z. Sun, “The androgen receptor negatively regulates the expression of cMet: implications for a novel mechanism of prostate cancer progression," Cancer Research, vol. 67, no. 3, pp. 967-975, 2007.

[18] M. Abdelrahim and S. Safe, "Cyclooxygenase-2 inhibitors decrease vascular endothelial growth factor expression in colon cancer cells by enhanced degradation of Sp1 and Sp4 proteins," Molecular Pharmacology, vol. 68, no. 2, pp. 317329, 2005.

[19] J. Wu, X. Ling, D. Pan et al., "Molecular mechanism of inhibition of Survivin transcription by the GC-rich sequenceselective DNA binding antitumor agent, hedamycin: evidence of Survivin down-regulation associated with drug sensitivity," Journal of Biological Chemistry, vol. 280, no. 10, pp. 97459751, 2005.

[20] L. Song, D. Li, Y. Gu et al., "MicroRNA-126 targeting PIK3R2 inhibits NSCLC A549 cell proliferation, migration, and invasion by regulation of PTEN/PI3K/AKT pathway," Clinical Lung Cancer, vol. 17, no. 5, pp. e65-e75, 2016.

[21] C. Feng, W. Rong, X. Jin, M. Jiang, and X. Zhu, "Her2 induces cell proliferation and invasion of non-small-cell lung cancer by upregulating Cox-2 expression via MEK/ERK signaling pathway," Oncotargets and Therapy, vol. 9, pp. 2709-2716, 2016.

[22] M. Santra, S. Santra, J. Zhang, and M. Chopp, "Ectopic decorin expression up-regulates VEGF expression in mouse cerebral endothelial cells via activation of the transcription factors Sp1, HIF1 $\alpha$, and STAT3," Journal of Neurochemistry, vol. 105, no. 2, pp. 324-337, 2008.

[23] N. Pore, S. Liu, H. K. Shu et al., "Sp1 is involved in AKTmediated induction of VEGF expression through an HIF-1independent mechanism," Molecular Biology of the Cell, vol. 15, no. 11, pp. 4841-4853, 2004.

[24] S. Wei, H. C. Chuang, W. C. Tsai et al., "Thiazolidinediones mimic glucose starvation in facilitating $\mathrm{Sp} 1$ degradation 
through the up-regulation of $\beta$-transducin repeat-containing protein," Molecular Pharmacology, vol. 76, no. 1, pp. 47-57, 2009.

[25] K. Beishline and J. Azizkhan-Clifford, "Sp1 and the 'hallmarks of cancer'," FEBS Journal, vol. 282, no. 2, pp. 224-258, 2015.

[26] J. Feng, Y. Zhang, and D. Xing, "Low-power laser irradiation (LPLI) promotes VEGF expression and vascular endothelial cell proliferation through the activation of ERK/Sp1 pathway," Cellular Signalling, vol. 24, no. 6, pp. 1116-1125, 2012.

[27] J. M. Curry, T. D. Eubank, R. D. Roberts et al., "M-CSF signals through the MAPK/ERK pathway via Sp1 to induce VEGF production and induces angiogenesis in vivo," PLOS One, vol. 3, no. 10, article e3405, 2008.

[28] K. Abdelmohsen and M. Gorospe, "RNA-binding protein nucleolin in disease," RNA Biology, vol. 9, no. 6, pp. 799-808, 2014.

[29] K. Abdelmohsen, K. Tominaga, E. K. Lee et al., "Enhanced translation by nucleolin via G-rich elements in coding and non-coding regions of target mRNAs," Nucleic Acids Research, vol. 39, no. 19, pp. 8513-8530, 2011.

[30] D. M. Wu, P. Zhang, R. Y. Liu et al., "Phosphorylation and changes in the distribution of nucleolin promote tumor metastasis via the PI3K/Akt pathway in colorectal carcinoma," FEBS Letters, vol. 588, no. 10, pp. 1921-1929, 2014.

[31] C. Y. Hung, W. B. Yang, S. A. Wang, T. I. Hsu, W. C. Chang, and J. J. Hung, "Nucleolin enhances internal ribosomal entry site (IRES)-mediated translation of Sp1 in tumorigenesis," Biochimica et Biophysica Acta, vol. 1843, no. 12, pp. 2843-2854, 2014.

[32] M. Nicolás, V. Noé, K. B. Jensen, and C. J. Ciudad, “Cloning and characterization of the $5^{\prime}$-flanking region of the human transcription FactorSp1Gene," Journal of Biological Chemistry, vol. 276, no. 25, pp. 22126-22132, 2001.

[33] Z. Lou, V. M. Maher, and J. J. McCormick, "Identification of the promoter of human transcription factor Sp3 and evidence of the role of factors Sp1 and Sp3 in the expression of Sp3 protein," Gene, vol. 351, no. 23, pp. 51-59, 2005.

[34] R. Xu, P. Zhang, J. Huang, S. F. Ge, J. Lu, and G. X. Qian, "Sp1 and Sp3 regulate basal transcription of the Survivin gene," Biochemical and Biophysical Research Communications, vol. 356, no. 1, pp. 286-292, 2007.

[35] C. Zhu, Q. Zhu, Z. Wu et al., "Isorhapontigenin induced cell growth inhibition and apoptosis by targeting EGFR-related pathways in prostate cancer," Journal of Cellular Physiology, vol. 233, no. 2, pp. 1104-1119, 2018.

[36] Y. X. Yan, J. X. Zhao, S. Han et al., "Tetramethylpyrazine induces SH-SY5Y cell differentiation toward the neuronal phenotype through activation of the PI3K/AKT/Sp1/Topoii $\beta$ pathway," European Journal of Cell Biology, vol. 94, no. 12, pp. 626-641, 2015.

[37] J. H. Park, S. R. Kim, H. J. An, W. J. Kim, M. Choe, and J. A. Han, "Esculetin promotes type I procollagen expression in human dermal fibroblasts through MAPK and PI3K/AKT pathways," Molecular and Cellular Biochemistry, vol. 368, no. 1-2, pp. 61-67, 2012.

[38] L. G. Wang and A. C. Ferrari, "Mithramycin targets Sp1 and the androgen receptor transcription level-potential therapeutic role in advanced prostate cancer," Translational Oncogenomics, vol. 1, pp. 19-31, 2006.

[39] I. Jutooru, G. Chadalapaka, P. Lei, and S. Safe, "Inhibition of $\mathrm{NF} \kappa \mathrm{B}$ and pancreatic cancer cell and tumor growth by curcu- min is dependent on specificity protein down-regulation," Journal of Biological Chemistry, vol. 285, no. 33, pp. 2533225344, 2010.

[40] A. Tapias, P. Monasterio, C. J. Ciudad, and V. Noé, "Characterization of the $5^{\prime}$-flanking region of the human transcription factor Sp3 gene," Biochimica et Biophysica Acta, vol. 1730, no. 2, pp. 126-136, 2005.

[41] S. Chintharlapalli, S. Papineni, M. Abdelrahim et al., "Oncogenic microRNA-27a is a target for anticancer agent methyl 2 -cyano-3,11-dioxo-18 $\beta$-olean-1,12-dien-30-oate in colon cancer cells," International Journal of Cancer, vol. 125, no. 8, pp. 1965-1974, 2009.

[42] C. H. Wu, Y. S. Ho, C. Y. Tsai et al., "In vitro and in vivo study of phloretin-induced apoptosis in human liver cancer cells involving inhibition of type II glucose transporter," International Journal of Cancer, vol. 124, no. 9, pp. 2210-2219, 2009.

[43] S. Haupt, M. Berger, Z. Goldberg, and Y. Haupt, "Apoptosis the p53 network," Journal of Cell Science, vol. 116, no. 20, pp. 4077-4085, 2003.

[44] D. W. Meek, "Regulation of the p53 response and its relationship to cancer1," Biochemical Journal, vol. 469, no. 3, pp. 325346, 2015.

[45] S. A. Innocente and J. M. Lee, "p53 is a NF-Y- and p21-independent, Sp1-dependent repressor of cyclin B1 transcription," FEBS Letters, vol. 579, no. 5, pp. 1001-1007, 2005.

[46] M. M. Tajrishi, R. Tuteja, and N. Tuteja, "Nucleolin: the most abundant multifunctional phosphoprotein of nucleolus," Communicative \& Integrative Biology, vol. 4, no. 3, pp. 267275, 2014.

[47] Z. Lou, S. O'Reilly, H. Liang, V. M. Maher, S. D. Sleight, and J. McCormick, "Down-regulation of overexpressed Sp1 protein in human fibrosarcoma cell lines inhibits tumor formation," Cancer Research, vol. 65, no. 3, pp. 1007-1017, 2005.

[48] X. H. Chen, L. L. Lu, H. P. Ke et al., "The TGF- $\beta$-induced up-regulation of NKG2DLs requires AKT/GSK-3 $\beta$-mediated stabilization of SP1," Journal of Cellular and Molecular Medicine, vol. 21, no. 5, pp. 860-870, 2017. 